\title{
UPDATES TO THE ASCE-41-13 PROVISIONS FOR THE NONLINEAR MODELING OF STEEL WIDE-FLANGE COLUMNS FOR PERFORMANCE-BASED EARTHQUAKE ENGINEERING
}

\author{
Alexander Hartloper*,a, Dimitrios Lignos ${ }^{\mathrm{a}}$ \\ aSwiss Federal Institute of Technology, Lausanne (EPFL), Dept. Architecture, Civil and Environmental Engineering, \\ Lausanne, Switzerland \\ alexander.hartloper@epfl.ch, dimitrios.lignos@epfl.ch
}

\begin{abstract}
Performance-based earthquake engineering requires numerical models that are able to reliably predict the expected component behavior of buildings under seismic excitations. The nonlinear modeling guidelines provided in ASCE-41-13 have historically been used in this context by practicing engineers. However, for steel wide-flange columns, the recommendations are primarily based on experimental data that was fairly limited until recently. This paper addresses many of the limitations present in ASCE-41-13 for the modeling of steel wide-flange columns. Recent experimental data from large- and full-scale tests on wide-flange steel columns, supplemented with detailed finite element studies, has been collected for a wide range of column cross-sections and applied compressive axial loads. Multiple regression analysis is utilized to develop multivariate predictive equations for the seismic response of steel wide-flange columns. It is found that the primary contributors that dominate the column response are the local web slenderness, member slenderness and the applied axial load ratio due to gravity loading. Guidelines for developing nonlinear component models for steel columns that can be directly used in both nonlinear static and dynamic analysis procedures are provided. The predicted responses are validated against test data that was not part of the original database. Furthermore, recommendations are proposed for modeling wide-flange columns subjected to varying axial loads as well as bidirectional loading; and a new limit for force-controlled elements is proposed for columns under high axial compressive loading and lateral drift demands.
\end{abstract}

Keywords: steel columns, nonlinear modeling provisions, performance-based earthquake engineering, ASCE-41.

\section{INTRODUCTION}

In the context of Performance-Based Earthquake Engineering (PBEE), nonlinear numerical analysis techniques are employed in order to compute the relevant engineering demand parameters (EDPs) of a building for structural and non-structural damage control. In order to properly estimate the EDPs for a building subjected to seismic excitations, it is advised to utilize a combination of nonlinear static and dynamic analysis procedures [1]. These numerical analysis techniques require that the structural components are modeled from the onset of yielding through softening. Reliable component models allow that the building performance is adequately estimated at selected performance levels associated with frequent seismic events, as well as low probability of occurrence earthquakes that may lead to structural collapse.

Practicing engineers typically use the ASCE-41-13 [2] nonlinear modeling guidelines for the seismic performance assessment of new and existing frame buildings. However, as the current guidelines for the modeling of steel wide-flange columns are nearly 30 years old, a number of limitations exist. A few of these limitations are summarized as follows: (1) the guidelines are suitable only for nonlinear static analysis procedures, and not for nonlinear dynamic analysis procedures; (2) column elements with $P / P_{c l} \geq 0.50$ are treated as force controlled, where $P_{c l}$ is the lower bound compressive strength of the respective column; (3) recommendations for columns that experience axial load variation due to dynamic overturning effects have been overlooked; and (4)

(C) Ernst \& Sohn Verlag für Architektur und technische Wissenschaften GmbH \& Co. KG, Berlin · CE/papers (2017) 
the effect of variations in the input parameters on the component response are not considered. More recent nonlinear modeling guidelines for structural steel components [3] have been implemented in the PEER/ATC-72 guidelines [4]. However, these recommendations focus mainly on steel beams rather than columns due to lack of steel column experimental data available at the time.

A number of recent testing programs have advanced the state of knowledge for the hysteretic behavior of wide-flange columns in steel frame lateral load resisting systems under combined axial load and lateral drift demands [5-9]. In combination with these experimental programs, detailed finite element studies have helped to expand on the behavior of a wide range of cross-sections and axial load demands $[10,11]$. The objective of this paper is to utilize recent data on steel wide-flange columns to develop a set of modeling recommendations that address the aforementioned issues present in ASCE-41-13.

Notably, the need to update the ASCE-41 nonlinear modeling provisions for several structural components has been pointed out in a recently funded project by the National Institute of Standards and Technology through the Applied Technology Council (ATC-114-Phase 1 [12-14]). This project covers a much broader scope. This paper specifically focuses on the development of proposed recommendations for modeling the nonlinear behavior of wide-flange steel columns in steel frame buildings under seismic excitations. The proposed modeling guidelines presented in this paper are intended to be used as a part of future updates to the ASCE-41 guidelines.

\section{PROPOSED MODELING RECOMMENDATIONS}

\subsection{Description of basic component model for columns}

Figure 1 shows the multi-linear component model used in the proposed recommendations. In the same figure, the current ASCE-41-13 [2] component model is also superimposed. In Figure 1, the variables $Q$ and $\Delta$ represent the steel column flexural strength, $M$, and the chord rotation, $\theta$, respectively. In this figure, the blue curve represents the monotonic curve of a steel column, which is considered to be a unique property of a structural component as discussed in [3]. In Figure 1, the red line represent the first-cycle envelope curve of a steel column subjected to a reversed cyclic symmetric loading history. Even though this curve is loading history dependent, it is used by practicing engineers in nonlinear static analysis procedures to inherently capture the effects of cyclic deterioration in strength and stiffness of structural components subjected to a consistent cyclic loading protocol.

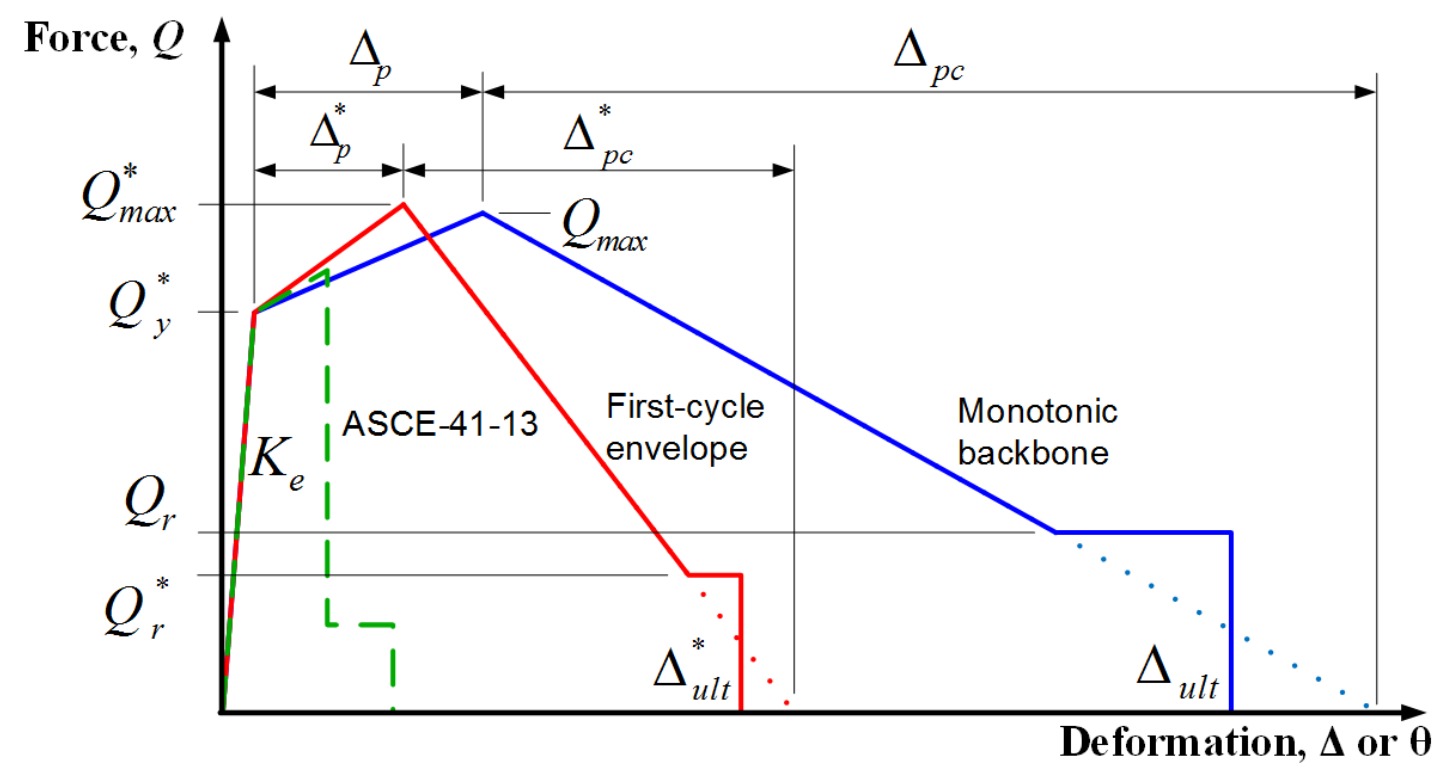

Fig. 1. Proposed component model and comparison with ASCE-41 component model

The column's elastic response is represented up to the effective flexural yield strength $Q^{*}$. Once flexural yielding occurs, the flexural strength increases due to hardening up to the peak, (or 
capping strength), $Q_{\max }$. Strength deterioration initiates due to local and/or lateral-torsional buckling at the pre-peak plastic deformation of $\Delta_{p}$. The post-peak plastic deformation, $\Delta_{p c}$, indicates the post-buckling behavior of the column, which is a controlling parameter for collapse assessment of deteriorating structural systems as discussed in Ibarra and Krawinkler [15] as well as other related studies [16, 17]. Local buckling stabilization [18] is observed once the structural component attains a residual strength, $Q_{r}$. Finally, failure will occur at the ultimate deformation of $\Delta_{u l t}$, likely due to the loss of axial load carrying capacity of the steel column.

\subsection{Parameter trends}

Figure 2 shows the trends of the pre-peak plastic rotation, $\theta_{p}$, with respect to the input model parameters for columns subjected to monotonic loading histories, while Figure 3 shows the relation between the same input variables, and the post-yield hardening ratio, $a=M_{\max } / M_{y}^{*}$. The data shown in Figures 2 and 3 used to develop the proposed modeling recommendations for steel wide-flange columns is taken from test data supplemented with detailed finite element studies [19]. In brief, over 180 data points were available for columns subjected to both monotonic and reversed cyclic loading histories. In Figures 2 and 3, for each plot, the red line is only shown to provide a sense of the trends present in the collected data.

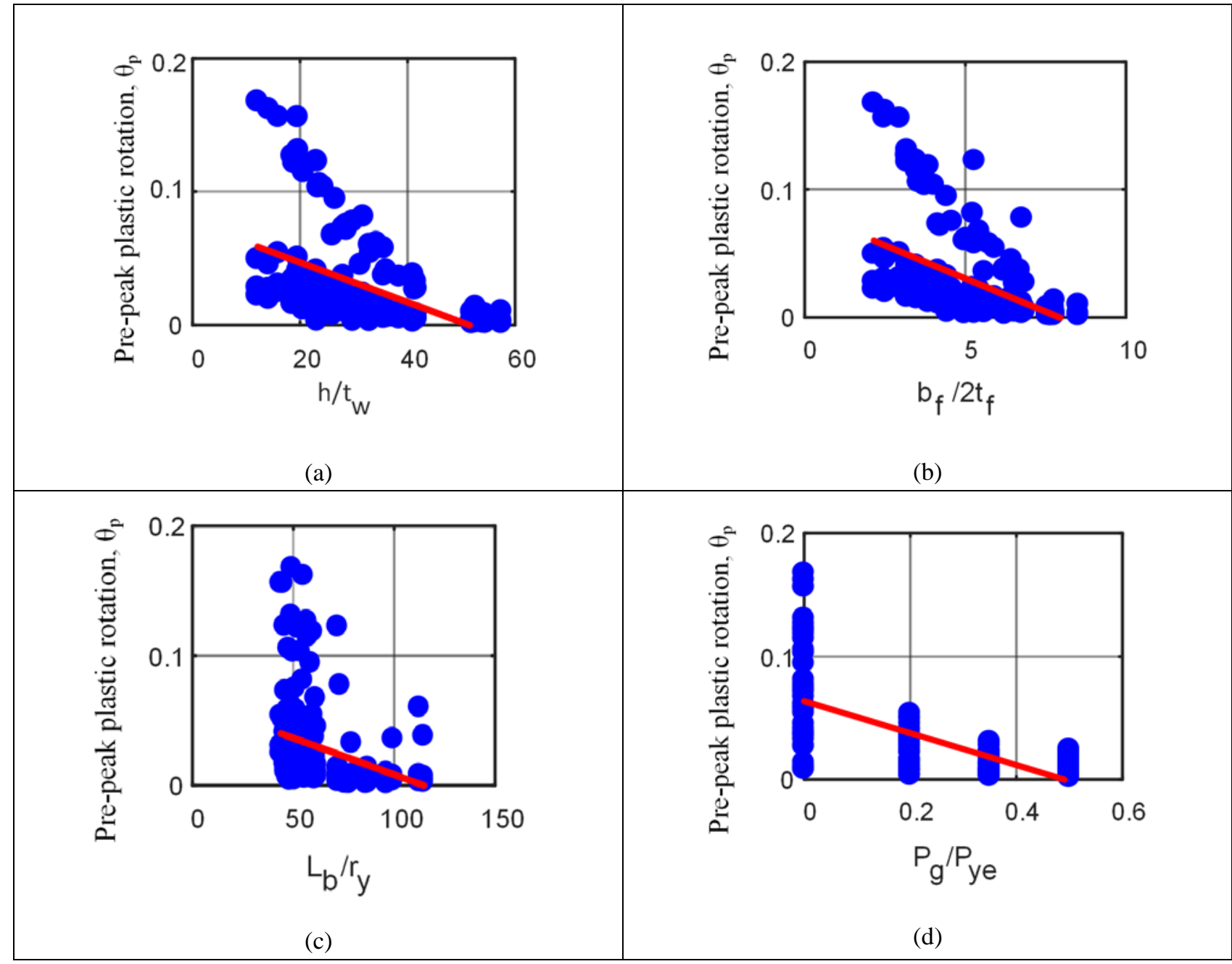

Fig. 2. Influence of model input parameters on the pre-peak plastic rotation, $\theta_{p}$

The web slenderness ratio, $h / t_{w}$, is found to be the most significant variable for representing the local cross-sectional slenderness (see Figures 2a, 3a). While the ratio of the unbraced length to the radius of gyration with respect to the weak-axis of the wide-flange cross section, $L_{b} / r_{y}$ (see Figures 2c, 3c), is found to best represent the global slenderness of the column [20]. The flange slenderness ratio, $b_{f} / 2 t_{f}$, is also found to be significant. However, due to the high collinearity 
between flange and web slenderness ratios, only $h / t_{w}$ is included in the multivariate regression equations as it is found to best predict the column response.

The influence of the axial load present on the column (see Figures 2d, 3d) is included through the ratio of the applied gravity load to expected axial yield strength, $P_{g} / P_{y e}$. Prior experimental studies [7] indicate that the constant gravity load is found to have a greater influence over the transient axial load resulting from dynamic overturning. This is a result of local buckling straightening within the plastic hinge region of the column. During cycles where the column experiences reduced axial load demands due to the transient effects in the response history, a straightening of the existing local buckles is observed [7,21]. Therefore, since the column behavior is primarily dependent on the constant gravity load, it can be predicted through the use of the constant gravity component only [20].

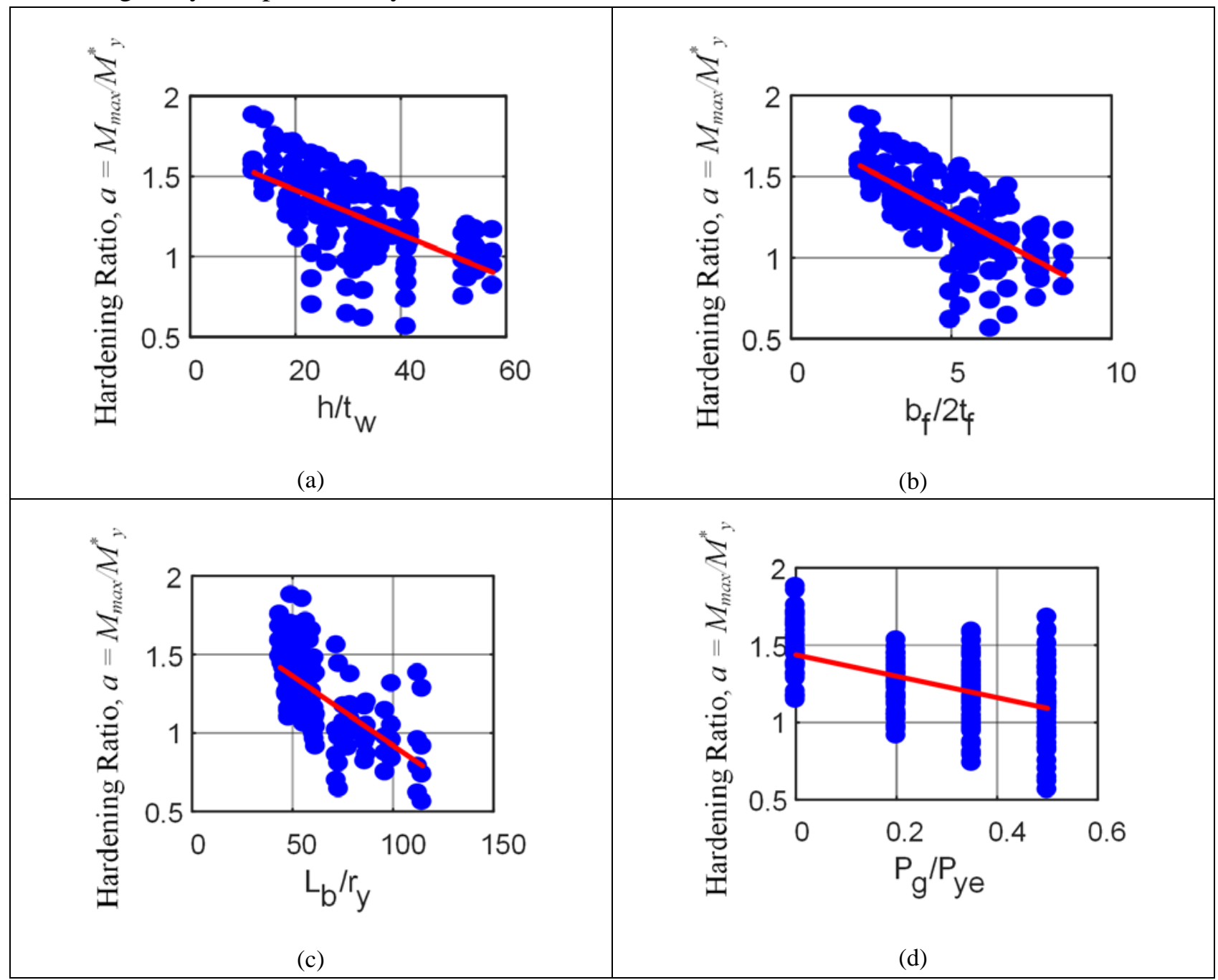

Fig. 3. Influence of model input parameters on $a=M_{\max } / M_{y}^{*}$

As observed in Figure 2, the pre-peak plastic rotation decreases with increasing local and global slenderness, as well as the applied axial load ratio. This is attributed to the earlier onset of local and/or lateral-torsional buckling. The same trends in the data hold true for the post-peak plastic deformation parameter [20]. Decreased post-peak plastic deformation is associated with accelerated deterioration as a result of an increase in local and/or global slenderness, and increased axial loading. Furthermore, as shown in Figure 3, similar observations can be made with regards to the trends observed for the post-yield hardening parameter with respect to each of the model input variables due to cyclic hardening. Therefore, the hardening ratio is strongly related with the crosssectional geometric properties and the applied axial load. This effect has been overlooked in ASCE41-13, where the post-yield hardening is assumed to be a constant $3 \%$ of the effective elastic stiffness, and does not consider additional input parameters [2]. The aforementioned observations 
made with regards to the parameter trends on $\theta_{p}, \theta_{p c}$ and $a$ hold true for columns subjected to both monotonic and reversed cyclic loading histories [20].

\subsection{Regression equations for monotonic backbone and first-cycle envelope curves}

The equations presented in this section are necessary to fully describe the component model shown in Figure 1. These equations are developed based on engineering mechanics in combination with multiple regression analysis of the database described in Section 2.2. The component model should capture the expected damage progression in steel wide-flange columns under combined axial loading and lateral drift demands. Therefore, the exponents in each of the multiple regression equations provided in this section should reflect the trends shown in Figures 2 and 3. The first-cycle envelope curve described in Figure 1 should be constructed for nonlinear static analysis procedures, and the monotonic backbone curve for dynamic analysis procedures provided that the employed component model explicitly simulates the effects of cyclic deterioration in strength and stiffness. This can be achieved the use of any deteriorating model (e.g., [15, 22]). An uncertainty in the component response exists due to variability in the input parameters. The variability can be attributed to differences in material properties, geometric properties, and construction practices. As it is impractical to take into account these variations directly, the mean response is calculated and the uncertainty of the response is taken into account through reporting a coefficient of variation (COV).

The effective elastic stiffness, $K_{e}$, should consider both flexure and shear deformations [23, 24]. Assuming double curvature in the column, the effective elastic flexural stiffness can be calculated using the equations to estimate the flexural stiffness of link beams in eccentrically braced frames per ASCE-41-13 [2]:

$$
\begin{aligned}
& K_{e}=\frac{K_{s} \cdot K_{b}}{K_{s}+K_{b}} \cdot \frac{L^{2}}{2} \\
& K_{s}=G A_{w} / L \\
& K_{b}=12 E I / L^{3}
\end{aligned}
$$

In which $K_{s}$ is the stiffness of the column considering shear deformations only, and $K_{b}$ is the stiffness considering flexure only. $G$ is the shear modulus of the steel material; $A_{w}$ is the area of the web; $L$ is the length of the column; $E$ is the elastic modulus of the steel material; and $I$ is the moment of inertia of the column.

Effective yield strength, $Q_{y}^{*}$ :

$$
M_{y}^{*}=\left\{\begin{array}{cc}
1.15 \cdot Z \cdot R_{y} \cdot F_{y}\left(1-P_{g} / 2 P_{y e}\right) & \text { if } P_{g} / P_{y e} \leq 0.20 \\
1.15 \cdot Z \cdot R_{y} \cdot F_{y}\left[9 / 8\left(1-P_{g} / P_{y e}\right)\right] & \text { if } P_{g} / P_{y e}>0.20
\end{array}\right.
$$

for Equation 2, the $C O V=0.10$. In which, $P_{g}$ is the column axial load due to gravity; $P_{y e}$ is the expected axial yield strength; $Z$ is the plastic section modulus of the column; $R_{y}$ is a factor to obtain the expected yield stress from Table A3.1 per AISC-341-10 [25]; and $F_{y}$ is the nominal yield stress of the respective steel material. Equation 2 is based on the AISC interaction equations, where the 1.15 factor accounts for the effects of cyclic hardening on the column flexural strength.

For the following equations, the superscript asterisk $(*)$ denotes the equations used for the first-cycle envelope, while the absence of the asterisk denotes the equations to be used for the monotonic backbone.

Peak (capping) strength, $Q_{\max }$ or $Q_{\max }^{*}: M_{\max }=a M_{y}^{*}$, or $M_{\max }^{*}=a^{*} M_{y}^{*}$ where

$$
a=12.5\left(\frac{h}{t_{w}}\right)^{-0.2}\left(\frac{L_{b}}{r_{y}}\right)^{-0.4}\left(1-\frac{P_{g}}{P_{y e}}\right)^{0.4} \geq 1.0,(C O V=0.10)
$$


$a^{*}=9.5\left(\frac{h}{t_{w}}\right)^{-0.4}\left(\frac{L_{b}}{r_{y}}\right)^{-0.16}\left(1-\frac{P_{g}}{P_{y e}}\right)^{0.2} \geq 1.0,(C O V=0.07)$

In Equations 3 and 4, if $P_{g} / P_{y e}>0.3$, or if $h / t_{w}<15$, then $a\left(\right.$ or $\left.a^{*}\right) \leq 1.3$.

Pre-peak plastic deformation, $\Delta_{p}$ or $\Delta_{p}^{*}$ :

$\theta_{p}=294\left(\frac{h}{t_{w}}\right)^{-1.7}\left(\frac{L_{b}}{r_{y}}\right)^{-0.7}\left(1-\frac{P_{g}}{P_{y e}}\right)^{1.6} \leq 0.20,(\operatorname{COV}=0.39)$

$\theta_{p}^{*}=15\left(\frac{h}{t_{w}}\right)^{-1.6}\left(\frac{L_{b}}{r_{y}}\right)^{-0.3}\left(1-\frac{P_{g}}{P_{y e}}\right)^{2.3} \leq 0.10,(C O V=0.31)$

Post-peak plastic deformation, $\Delta_{p c}$ or $\Delta_{p c}^{*}$ :

$\theta_{p c}=90\left(\frac{h}{t_{w}}\right)^{-0.8}\left(\frac{L_{b}}{r_{y}}\right)^{-0.8}\left(1-\frac{P_{g}}{P_{y e}}\right)^{2.5} \leq 0.30,(C O V=0.26)$
$\theta_{p c}^{*}=14\left(\frac{h}{t_{w}}\right)^{-0.8}\left(\frac{L_{b}}{r_{y}}\right)^{-0.5}\left(1-\frac{P_{g}}{P_{y e}}\right)^{3.2} \leq 0.10,(C O V=0.42)$

Residual strength, $Q_{r}$ or $Q_{r}^{*}$ :

$M_{r}=\left(0.5-0.4 \frac{P_{g}}{P_{y e}}\right) M_{y}^{*},(C O V=0.27)$
$M_{r}^{*}=\left(0.4-0.4 \frac{P_{g}}{P_{y e}}\right) M_{y}^{*},(C O V=0.35)$

Ultimate deformation, $\Delta_{u l t}$ or $\Delta_{u l t}^{*}$ :

$\theta_{u l t}=0.15$ radians, $(C O V=0.46)$

$\theta_{u l t}^{*}=0.08\left(1-0.6 P_{g} / P_{y e}\right)$ radians, $(C O V=0.51)$

The geometric limits on Equations 2 through 12 are:

$3.71 \leq h / t_{w} \leq 57.51 .82 \leq b_{f} / 2 t_{f} \leq 8.5238 .4 \leq L_{b} / r_{y} \leq 120$

Equations 2 to 12 are developed for ASTM A992 Grade $50\left(F_{y}=345 \mathrm{MPa}\right)$ steel or equivalent. Additionally, columns with $P_{g} / P_{y e}>0.60$ that have $h / t_{w}>43$ and $K L / r_{y}>120$ should be treated as force-controlled as per ASCE-41-13 [2]. This agrees with recent findings by Bech et al. [24].

\subsection{Comparison with experimental data}

Comparisons between the predicted responses based on the equations provided in Section 2.3 and the results from large-scale experimental programs are made in order to validate the proposed recommendations. To avoid bias in the comparisons, the predicted responses are compared against experimental data that was not part of the dataset used in the regression analysis. Figure 4a shows the comparison for a W14X82 section with $P_{g} / P_{y e}=0.30$ subjected to monotonic loading tested by Lignos et al [8]. Figure $4 \mathrm{~b}$ shows the comparison for the same cross-section with an axial load of $P_{g} / P_{y e}=0.50$ subjected to reversed cyclic loading tested by Elkady and Lignos [26]. In each of the figures, the blue and red curves show the predicted responses from Section 2.3 for the monotonic 
and first-cycle backbones, respectively. The green curve shows the prediction provided by the current ASCE-41 component model.

From Figure 4, it is seen that the predictive equations represent fairly well the test data, especially when compared against the ASCE-41 component model predictions. Both the pre- and post-peak plastic deformation parameters are reasonably predicted, irrespective of the column crosssection or axial load ratio. Notably, the proposed guidelines are able to capture the gradual decrease in flexural strength in the post-buckling region. In the same figure, it is seen that the post-yield hardening is reasonably predicted for both monotonic and cyclic loading. The proposed component models are able to capture variations in the post-yield hardening ratio due to local and global slenderness as well as the applied axial load.

Furthermore, from Figure 4b the column loaded with $P_{g} / P_{y e}=0.50$ (i.e., $P / P_{c r}>0.50$ ) has a considerable plastic deformation capacity. In the same figure, the predicted column response specified by ASCE-41-13 is force-controlled. This suggests that the current ASCE-41-13 limit for force-controlled elements should be revised. Based on the collected data, it is found that when $P_{g} / P_{y e} \geq 0.60$, as well as $h / t_{w}>43$ and $K L / r_{y}>120$ then steel wide-flange columns should be treated as force-controlled elements [24].

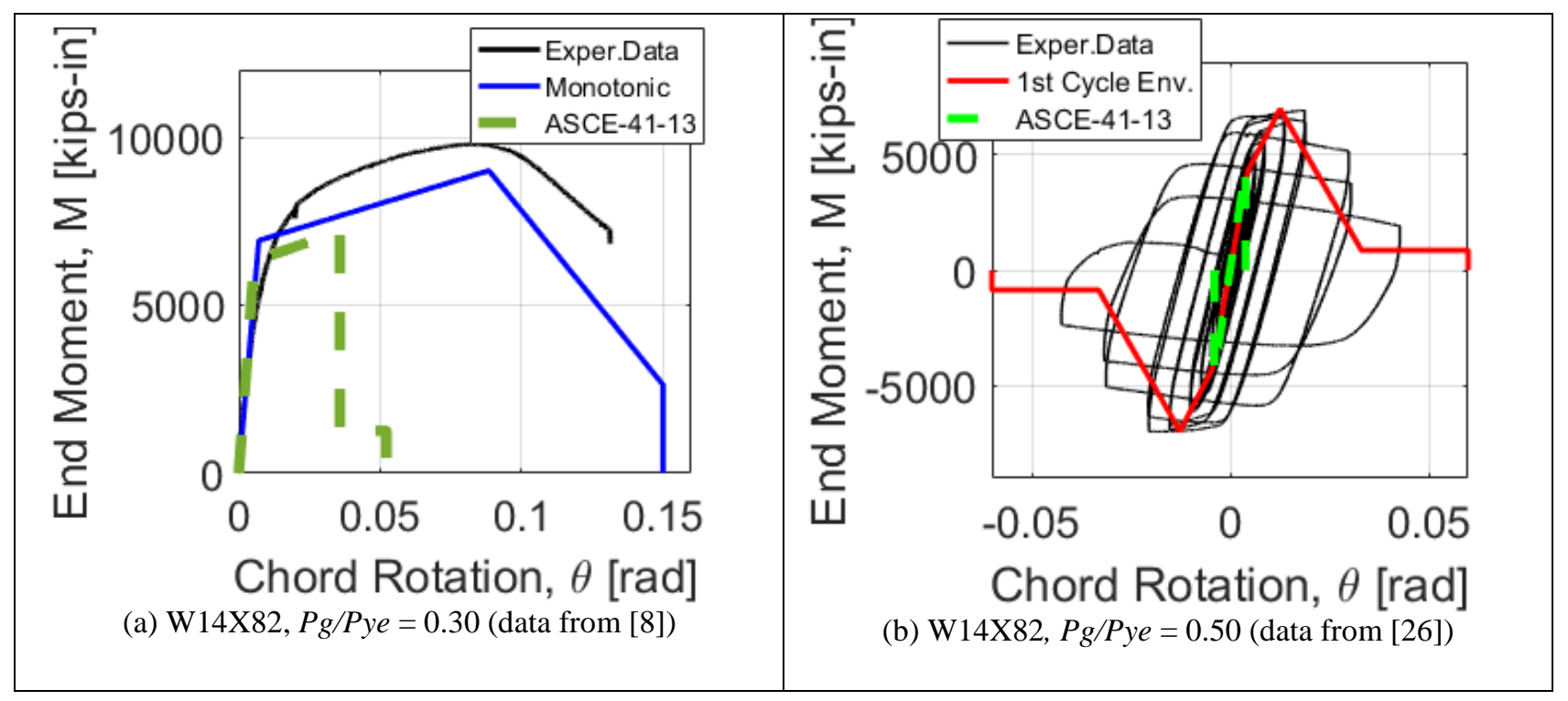

Fig. 4. Comparison of predictive equations with test data

\subsection{Modeling of steel columns under bidirectional loading}

The deduced first-cycle envelope curves of nominally identical columns tested under constant axially compressive loading, combined with unidirectional or bidirectional lateral loading are shown in Figure 5. In particular, the first cycle envelope curves of the W24X146 and W24X84 columns with $P_{g} / P_{y e}=0.20$ tested by Elkady and Lignos [9, 26] are shown in Figures 5a and 5b, respectively. From Figure 5 it is seen that the plastic deformation parameters are consistent for the columns subjected to both unidirectional and bidirectional lateral drift demands. Therefore, it is recommended that the proposed modeling guidelines for unidirectional lateral loading be implemented for columns under bidirectional lateral loading. The parameters of the component model shown in Figure 1 may be used for columns under bidirectional lateral loading, and the equations presented in Section 2.3 are to be used. Due to brevity, further details regarding this issue are discussed in Hartloper [20] and Elkady and Lignos [9].

\subsection{Modeling of steel columns under varying axial load}

As discussed in Section 2.2, the constant axially compressive load due to gravity has a dominant effect over the transient component resulting from dynamic overturning effects. This is a result of the straightening of local buckles in the plastic hinge region during periods when the axial load is lessened. Therefore, the constant gravity load, $P_{g}$, can be used in constructing component models for columns under varying axial loads. Thus, the equations provided in Section 2.3 should be 
employed for columns experiencing varying axial loads. The development of component models for such columns subjected to varying axial loads is therefore simplified, as the gravity load on the column is known prior to the development of the numerical building model. The alternative in this case would be to utilize more complex numerical models than the one presented in Figure 1 that explicitly capture the axial force-bending interaction within the cross-section as well as cyclic deterioration due to geometric instabilities. An example of such models is presented in [22].

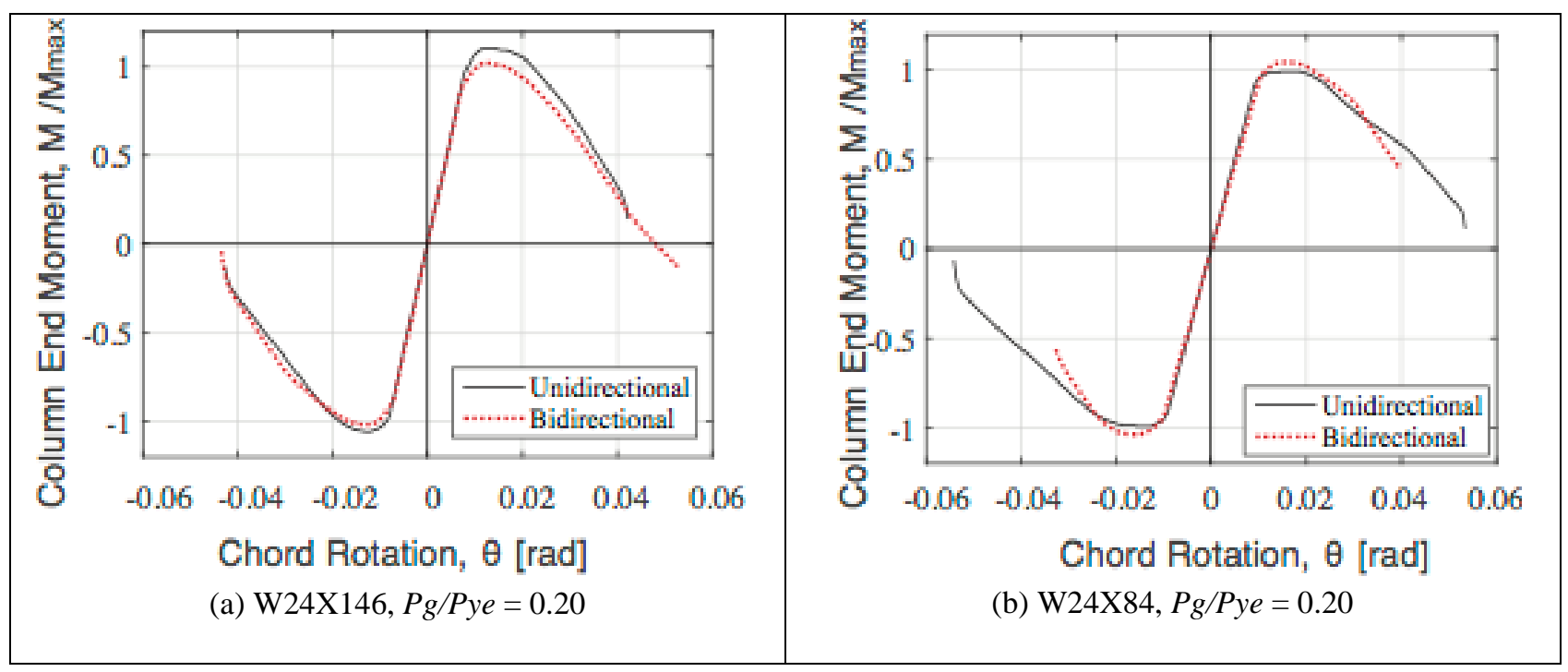

Fig. 5. Comparison of columns under unidirectional and bidirectional lateral loading (data and images from [26])

\section{CONCLUSIONS}

This paper presents a summary of the many improvements to the nonlinear modeling of wide-flange columns in conventional steel frame seismic force resisting systems. Recent test data, supported by results from detailed finite element studies, is analyzed using multiple regression analysis. From this, empirical relations are derived between the column's plastic deformation and post-yield hardening parameters, and the model input variables. Guidance is provided for the development of component models for both nonlinear static and dynamic analysis procedures. The proposed equations predict the monotonic and first-cycle envelope curves of wide-flange steel columns experiencing deterioration mechanisms under combined axial loading and lateral drift demands. The various deterioration mechanisms are accounted for through considering the effects of the crosssectional local and global slenderness, as well as the axial load present on the column. The variability of the model input variables on each of the response parameters is taken account of through a COV.

The main conclusions with regards to the developments presented in this paper are summarized as follows:

- The proposed recommendations provide a reasonably accurate prediction of the plastic deformation and post-yield hardening parameters for wide-flange steel columns under seismic excitations. The physical steel column behavior can be reasonably predicted independently of the column cross-section or axial load ratio, and for both reversed-cyclic and monotonic loading histories.

- The proposed component models can capture the gradual decrease in flexural strength in the post-peak region. This has important implications for the numerical analysis of buildings, because the current ASCE-41 component model may experience difficulties converging in the negative stiffness region due to the sharp drop-off in flexural strength.

- The post-yield hardening ratio is shown to be significantly related to the cross-section geometry and axial load ratio of the column. The variations in the post-yield hardening based on the model input parameters are considered in the proposed recommendations. This issue has been previously overlooked in the ASCE-41-13 guidelines for steel wide-flange columns. 
- The constant axial gravity load, $P_{g}$, has been shown to have a dominant effect on the response of wide-flange columns. The transient component of the axial load has a reduced effect since it has been observed that the local buckles straighten as the axial load is lessened. Therefore, it is recommended that the constant load $P_{g}$ be used when constructing component models for steel wide-flange columns subjected to varying axial loads.

- It was found that steel wide-flange columns have considerable plastic deformation capacity under axial loads of $P / P_{c l} \geq 0.50$. Therefore, the force-controlled limit in ASCE-41-13 should be revised to $P_{g} / P_{y e} \geq 0.60$ for steel wide-flange columns with as $h / t_{w}>43$ and $K L / r_{y}>120$. This revision may not necessarily have implications related to the seismic performance of modern steel frame buildings; however, it may be critical in cases that seismic retrofit is needed in existing steel frame buildings that were designed without today's capacity design principles.

- The plastic deformation parameters for wide-flange columns under bidirectional and unidirectional loading are nearly equivalent. It is therefore recommended that the proposed guidelines for steel wide-flange columns under unidirectional lateral loading be applied to columns under bidirectional lateral loading.

\section{ACKNOWLEDGMENTS}

This paper relies on results obtained under Task Order 38 of the NEHRP Consultants Joint Venture (a partnership of the Applied Technology Council and Consortium of Universities for Research in Earthquake Engineering), under Contract 1140-22-025, Earthquake Structural and Engineering Research, issued by the National Institute of Standards and Technology. The views expressed in the paper are those of the authors and do not necessarily represent those of the sponsors identified above.

\section{REFERENCES}

[1] Lignos, D. G., Putman, C., Krawinkler, H. "Application of simplified analysis procedures for performance-based earthquake evaluation of steel special moment frames", Earthquake Spectra 31, No. 4, pp. 1949-1968, 2015

[2] ASCE. "Seismic evaluation and retrofit of existing buildings, ASCE 41-13". American Society of Civil Engineers, Reston, Virginia, United States, 2014

[3] Lignos, D. G., Krawinkler, H. "Deterioration modeling of steel components in support of collapse prediction of steel moment frames under earthquake loading”, Journal of Structural Engineering 137, No. 11, 2011

[4] PEER/ATC. "Modeling and acceptance criteria for seismic design and analysis of tall buildings". Report No. 72-1, Pacific Earthquake Engineering Research Center (PEER) and Applied Technology Council (ATC), 2010

[5] MacRae, G. A. "The seismic response of steel frames”. University of Canterbury, Christchurch, New Zealand, 1989

[6] Newell, J. D., Uang, C.-M. "Cyclic behavior of steel columns with combined high axial load and drift demand". University of California, San Diego, California, United States, 2006

[7] Suzuki, Y., and Lignos, D. G. "Large scale collapse experiments of wide flange steel beam-columns", Proceedings of the $8^{\text {th }}$ International Conference on Behavior of Steel Structures in Seismic Areas (STESSA), Shanghai, China, 2015

[8] Lignos, D. G., Cravero, J., Elkady, A. "Experimental investigation of the hysteretic behavior of wideflange steel columns under high axial load and lateral drift demands", Proceedings of the $11^{\text {th }}$ Pacific Structural Steel Conference, Shanghai, China, 2016

[9] Elkady A., Lignos, D. G. "Full-scale cyclic testing of deep slender wide-flange steel beam-columns under unidirectional and bidirectional lateral drift demands", Proceedings of the $16^{\text {th }}$ World Conference on Earthquake Engineering (16WCEE), Santiago Chile, 2017

[10] Elkady, A., and Lignos, D. G. "Analytical investigation of the cyclic behavior and plastic hinge formation in deep wide-flange steel beam-columns”, Bulletin of Earthquake Engineering 13, No. 4, pp. 1097-1118, 2015 
[11] Fogarty, J., El-Tawil, S. "Collapse resistance of steel columns under combined axial and lateral loading”, Journal of Structural Engineering 142, No. 1, 2015

[12] ATC. "Guidelines for nonlinear structural analysis for design of buildings: Part IIa—steel moment frames". Applied Technology Council, 2016

[13] Hamburger, R., Deierleien, G., Lehman, D., Lowes, L., Shing, B., Van de Lindt, J., Lignos., D. G., Hortacsu, A. "ATC-114 next generation hysteretic relationships for performance-based modeling and analysis", Proceedings of the Structural Engineers Association of California (SEAOC) Convention, Hawaii, USA, 2016

[14] Haselton, C., Deierleien, G., Bono, S., Ghannoum, W., Hachem, M., Malley, J., Hooper, J., Lignos, D. G., Mazzoni, S., Pujol, S. "Guidelines on nonlinear dynamic analysis for performance-based seismic design of steel and concrete moment frames", Proceedings of the Structural Engineers Association of California (SEAOC) Convention, Hawaii, USA, 2016

[15] Ibarra, L. F., Krawinkler, H. “Global collapse of frame structures under seismic excitations”. Report No. 152, The John A. Blume Earthquake Engineering Center, Stanford University, 2005

[16] Zareian, F., Lignos, D. G., Krawinkler, H. "Modeling of component deterioration for collapse prediction of steel moment frames", Proceedings of the $6^{\text {th }}$ International Conference on Behavior of Steel Structures in Seismic Areas (STESSA), Philadelphia, USA, 2009

[17] Krawinkler, H. Zareian, F., Lignos, D. G., Ibarra, L. F. "Significance of modeling deterioration in structural components for predicting the collapse potential of structures under earthquake excitations". Chapter 16, Advances in Performance-Based Earthquake Engineering, Geotechnical, Geological and Earthquake Engineering 13, 2010

[18] Krawinkler, H., Zohrei, M., Lashkari-Irvani, B., Cofie, N., Hadidi-Tamjed, H. "Recommendations for experimental studies on the seismic behavior of steel components and materials". Report No. 61, The John A. Blume Earthquake Engineering Center, Stanford University, 1983

[19] Elkady, A. "Collapse risk assessment of steel moment resisting frames designed with deep wide-flange columns in seismic regions”. McGill University, Montreal, Quebec, Canada, 2016

[20] Hartloper, A. R. "Updates to the ASCE-41-13 nonlinear modelling provisions for performance-based seismic assessment of new and existing steel moment resisting frames”. McGill University, Montreal, Quebec, Canada, 2016

[21] Suzuki, Y., Lignos, D. G. "Development of loading protocols for experimental testing of steel columns subjected to combined lateral drift and high axial load", Proceedings of the $10^{\text {th }}$ National Conference on Earthquake Engineering (NCEE), Anchorage, USA, 2014

[22] Suzuki, Y., Lignos, D. G. "Collapse behavior of steel columns as part of steel frame buildings: experiments and numerical models", Proceedings of the $16^{\text {th }}$ World Conference on Earthquake Engineering (16WCEE), Santiago Chile, 2017

[23] Newell, J. "Cyclic Behaviour and design of steel columns subjected to large drift". University of California, San Diego, USA, 2008

[24] Bech, D., Tremayne, B., Houston, J. "Proposed changes to steel column evaluation criteria for existing buildings”, Proceedings of the ATC/SEI $2^{\text {nd }}$ Conference on Improving the Seismic Performance of Existing Buildings and Other Structures, San Francisco, California, United States, pp. 255-272, 2015

[25] AISC. "Seismic provisions for structural steel buildings, ANSI/AISC 341-10". American Institute of Steel Construction, Chicago, Illinois, United States, 2010

[26] Elkady, A., Lignos, D. G. "Dynamic stability of deep and slender wide-flange steel columns — full scale experiments". Proceedings of the Annual Stability Conference, Structural Stability Research Council (SSRC), Orlando, Florida, United States, 2016 